\title{
Botanical Briefs: Phytophotodermatitis Is an Occupational and Recreational Dermatosis in the Limelight
}

\author{
Simon C. Janusz, BS; Robert A. Schwartz, MD, MPH
}

\section{PRACTICE POINTS}

- Phytophotodermatitis (PPD) can be both an occupational and recreational dermatosis.

- Phytophotodermatitis is a nonallergic contact dermatitis and thus is independent of the immune system, so prior sensitization is not required.

- Individuals who work with plants should be aware of PPD and methods of prevention.

- Phytophotodermatitis may be evident only as asymptomatic hyperpigmentation.

Phytophotodermatitis (PPD) is a toxic reaction resulting from contact with a photosensitizing botanical chemical followed by exposure to solar or artificial UV light. It may present with bizarre patterns and linear streaks due to a phototoxic agent splashing onto various cutaneous sites; thus, it affects the skin at points of contact and exposure to UV light. Individuals typically experience symptoms within 24 hours of exposure. Children and adolescents seem particularly prone to developing PPD, as they tend to spend time in the sun and also may come into contact with common irritants such as wild parsley in lawn grass or beverages flavored with lime. However, PPD may be more than a recreational dermatitis; it also may represent a serious occupational dermatosis. In any case, the resultant acute dermatitis may be mild or severe with painful bullae and occasionally is more prominently evident as postinflammatory hyperpigmentation.

Cutis. 2021;107:187-189.

$\square$ hytophotodermatitis (PPD) is a nonallergic contact dermatitis and thus is independent of the immune system, so prior sensitization is not required. ${ }^{1-3}$ It sometimes is known by colorful names such as margarita photodermatitis, in which a slice of lime in a refreshing summer drink may be etiologic, 4,5 or berloque dermatitis, caused by exposure to perfumes containing bergapten (5-methoxypsoralen). ${ }^{6,7}$ Phytophotodermatitis may develop when phototoxic agents such as furocoumarins, which protect plants from fungal pathogens, and psoralens are applied to the skin followed by exposure to UV light, more specifically in the UVA range of 320 to $400 \mathrm{~nm}$. Thus, these chemicals produce a phototoxic rather than photoallergic reaction, leading to cellular damage. Furocoumarins and psoralens often are found in plants such as celery and figs as well as in citrus fruits such as limes, lemons, and grapefruits. Exposure may be cryptic, as the patient may not consider or mention the eruption as possibly caused by activities such as soaking one's feet in a folk remedy containing fig leaves. ${ }^{7,8}$ Once these phototoxic agents come in contact with the skin, the symptoms of PPD may arise within 24 hours of exposure, beginning as an acute dermatitis with erythema, edema, vesicles, or bullae accompanied by pain and itching.

\section{Etiology}

Phytophotodermatitis is caused by exposure to several different types of plants, including Ficus carica (common fig), the genus Citrus (eg, lime, lemon), or Pastina sativa (wild parsnip). Each of these contain furocoumarins and psoralens-phototoxic agents that cause cellular damage with epidermal necrosis and resultant pain when the skin is exposed to UVA light. ${ }^{1-4}$ There are 2 types of photochemical reactions in PPD: type I reactions occur in the absence of oxygen, whereas oxygen is present in type II reactions. Both damage cell membranes and DNA, which then results in DNA interstrand crosslinking between the psoralen furan ring and the thymine or cytosine of DNA, activating arachidonic acid metabolic pathways to produce cell death. ${ }^{1}$

From Rutgers New Jersey Medical School, Newark. Dr. Schwartz from the Departments of Dermatology, Pathology, Pediatrics, and Medicine. Mr. Janusz also is from Saint Joseph University, Philadelphia, Pennsylvania.

The authors report no conflict of interest.

Correspondence: Robert A. Schwartz, MD, MPH, Rutgers New Jersey Medical School, 185 South Orange Ave, Newark, NJ 07103-2714 (roschwar@cal.berkeley.edu).

doi:10.12788/cutis.0225 


\section{Epidemiology}

The incidence of PPD is unknown due to the high variability of reactions in individuals spanning from children to the elderly. It can be caused by many different wild and domestic plants in many areas of the world and can affect any individual regardless of age, race, gender, or ethnicity. Some individuals may be affected by hyperpigmentation without prominent inflammation. ${ }^{8}$ Diagnosis of PPD can be challenging, and an occupation and recreational history of exposure or recent travel with possible contact with plants may be required.

\section{Occupational Dermatitis}

Phytophotodermatitis also may be an occupational disease. .-12 $^{-12}$ Occupational exposure may occur in soldiers during military drills and other activities, farm workers, chefs, gardeners, groundskeepers, food processors, bartenders, and florists. Wearing protective gloves when handling plants such as limes, lemons, grapefruit, celery, or parsnips may prevent occupational exposure. Exposure to hogweed, an invasive species originally introduced as an ornamental plant in Europe and the United States, can produce a dramatic acute photodermatitis from exposure to its sap, which contains the psoralens 5-methoxypsoralen and 8-methylpsoralen.-11

\section{Recreational Dermatitis}

Phytophotodermatitis may be caused by exposure to phototoxic agents during leisure activities. Recreational exposure can occur almost anywhere, including in the kitchen, backyard, park, or woods, as well as at the beach. One notable culprit in recreational PPD is cooking with limes, parsley, or parsnips - plants that often are employed as garnishes in dishes, allowing early exposure of juices on the hands. Individuals who garden recreationally should be aware of ornamental plants such as hogweed and figs, which are notorious for causing PPD. ${ }^{13}$ Children's camp counselors should have knowledge of PPD, as children have considerable curiosity and may touch or play with attractive plants such as hogweed. Children enjoying sports in parks can accidentally fall onto or be exposed to wild parsnip or hogweed growing nearby and wake up the next day with erythema and burning. ${ }^{14}$ Photoprotection is important, but sunscreens containing carrot extract can produce PPD. ${ }^{15}$ Widespread PPD over $80 \%$ of the body surface area due to sunbathing after applying fig leaf tea as a tanning agent has been described. ${ }^{16}$ Eating figs does not cause photosensitization unless the juice is smeared onto the skin. Margarita dermatitis and "Mexican beer dermatitis" can occur due to limes and other citrus fruits being used as ingredients in summer drinks. ${ }^{5}$ Similarly, preparing sangria may produce PPD from lime and lemon juices. ${ }^{17}$ In one report, hiking in Corsica resulted in PPD following incidental contact with the endemic plant Peucedanum paniculatum. ${ }^{18}$

\section{Perfume (Berloque) Dermatitis}

Perfume dermatitis, or berloque dermatitis, is a type of PPD for which the name is derived from the German word berlock or the French word berloque meaning trinket or charm; it was first described in 1925 by Rosenthal ${ }^{7}$ with regard to pendantlike streaks of pigmentation on the neck, face, arms, or trunk. The dermatitis develops due to bergapten, a component of bergamot oil, which is derived from the rind of Citrus bergamia. Many perfumes contain bergamot oil, but the incidence of this condition has been diminished due to use of artificial bergamot oil. ${ }^{6}$

\section{Clinical Manifestation}

Phytophotodermatitis is first evident as erythematous patches that appear within 24 hours of initial exposure to a phototoxic agent and UVA light, sometimes with a burning sensation. Solar exposure within 48 hours of sufficient plant exposure is required. Perfuse sweating may enhance the reaction. ${ }^{19}$ Rarely, it first may be seen with the sudden appearance of asymptomatic hyperpigmentation. One may see the pattern of splash marks from lime or lemon juice (Figure 1). The acute dermatitis may be associated with adjacent cutaneous edema near the reaction site or along with the erythema and blister formation. Its severity is related to the intensity of sun exposure and amount of furocoumarins. ${ }^{2}$ The most common etiologic plants are citrus fruits such as limes and lemons, but it also can be caused by celery, figs, parsley, parsnips, and even mustard. ${ }^{1-3,12}$ Wild parsley may grow in grass, producing a bizarre pattern on the back in children who lay in the grass and then spend time in the sun. Phytophotodermatitis usually is followed by postinflammatory hyperpigmentation, which may be the principal or only finding in some individuals. ${ }^{8}$

\section{Differential Diagnosis}

Phytophotodermatitis may resemble other types of dermatitis, particularly other forms of contact dermatitis such poison ivy, and occasionally other environmental simulants such as jellyfish stings. ${ }^{1-6,20,21}$ Photosensitizing disorders including porphyria cutanea tarda, pseudoporphyria, and lupus erythematosus must be distinguished from PPD. ${ }^{22-24}$ Photosensitizing medications such tetracyclines, thiazide diuretics, sulfonamides, griseofulvin, and sulfonylureas should be considered. Airborne contact dermatitis may resemble PPD, as when poison ivy is burned and is

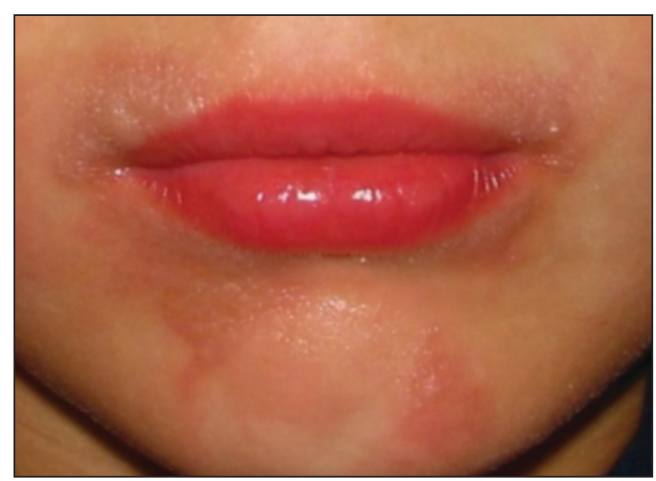

FIGURE 1. Erythema on the face of a 9-year-old boy following a splash pattern after drinking lime juice on a sunny day. 


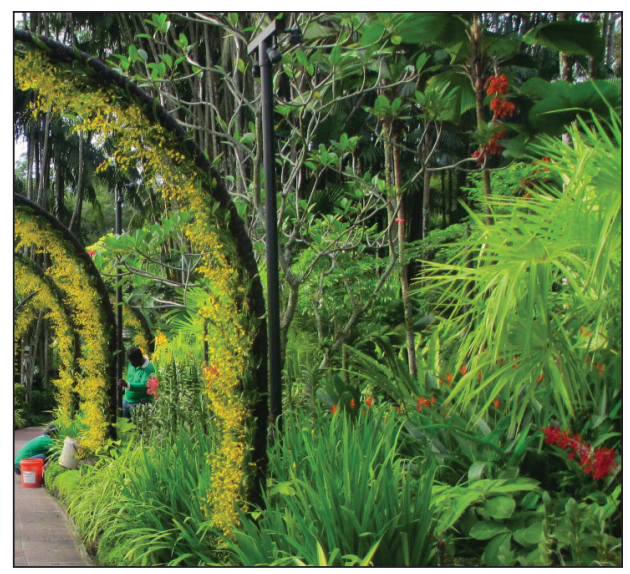

FIGURE 2. Workers employing limited cutaneous protection at the Singapore Botanic Gardens. Photograph courtesy of Robert A. Schwartz, MD, MPH.

exposed to the skin in sites of airborne contact. ${ }^{20}$ Excessive solar exposure is popular, particularly among adolescents, so sunburn and sunburnlike reactions can be noteworthy. ${ }^{25,26}$

\section{Treatment}

Phytophotodermatitis can be treated with topical steroids, sometimes adding an oral antihistamine, and occasionally oral steroids. ${ }^{2-4}$ Localized pain or a burning sensation should respond to therapy. Alternatively, a cold compress applied to the skin can relieve the pain and pruritus, and the burn can be debrided and dressed daily with silver sulfadiazine plus an oral nonsteroidal anti-inflammatory drug. This eruption should be self-limited as long as it is recognized early and the cause avoided. Management of acute exposure includes prompt application of soap and water and avoidance of UV light exposure for 48 to 72 hours to prevent psoralen photoactivation.

Because PPD is essentially a chemical burn, a burn protocol and possible referral to a burn center may be needed, whether the reaction is acute or widespread. $11,12,14,27,28$ Surgical debridement and skin grafting rarely may be mandated. ${ }^{14}$ Postinflammatory hyperpigmentation may ensue as the dermatitis resolves but is not common.

The best approach for PPD is prevention (Figure 2). Individuals who are at risk should be aware of their surroundings and potential plants of concern and employ personal protective equipment to shield the skin from plant sap, which should be promptly removed if it comes in contact with the skin.

\section{REFERENCES}

1. Zhang R, Zhu W. Phytophotodermatitis due to Chinese herbal medicine decoction. Indian J Dermatol. 2011;56:329-331.

2. Harshman J, Quan Y, Hsiang D. Phytophotodermatitis: rash with many faces. Can Fam Physician. 2017;63:938-940.

3. Imen MS, Ahmadabadi A, Tavousi SH, et al. The curious cases of burn by fig tree leaves. Indian J Dermatol. 2019;64:71-73.
4. Hankinson A, Lloyd B, Alweis R. Lime-induced phytophotodermatitis [published online September 29, 2014]. J Community Hosp Intern Med Perspect. doi:10.3402/jchimp.v4.25090

5. Abramowitz AI, Resnik KS, Cohen KR. Margarita photodermatitis. N Engl J Med. 2013;328:891.

6. Quaak MS, Martens H, Hassing RJ, et al. The sunny side of lime. J Travel Med. 2012;19:327-328.

7. Rosenthal O. Berloque dermatitis: Berliner Dermatologische Gesellschaft. Dermatol Zeitschrift. 1925;42:295.

8. Choi JY, Hwang S, Lee SH, et al. Asymptomatic hyperpigmentation without preceding inflammation as a clinical feature of citrus fruitsinduced phytophotodermatitis. Ann Dermatol. 2018;30:75-78.

9. Wynn P, Bell S. Phytophotodermatitis in grounds operatives. Occup Med (Lond). 2005;55:393-395.

10. Klimaszyk P, Klimaszyk D, Piotrowiak M, et al. Unusual complications after occupational exposure to giant hogweed (Heracleum mantegazzianum): a case report. Int J Occup Med Environ Health. 2014;27:141-144.

11. Downs JW, Cumpston KL, Feldman MJ. Giant hogweed phytophotodermatitis. Clin Toxicol (Phila). 2019;57:822-823.

12. Maso MJ, Ruszkowski AM, Bauerle J, et al. Celery phytophotodermatitis in a chef. Arch Dermatol. 1991;127:912-913.

13. Derraik JG, Rademaker M. Phytophotodermatitis caused by contact with a fig tree (Ficus carica). New Zealand Med J. 2007;120:U2720.

14. Chan JC, Sullivan PJ, O'Sullivan MJ, et al. Full thickness burn caused by exposure to giant hogweed: delayed presentation, histological features and surgical management. I Plast Reconstr Aesthet Surg. 2011;64:128-130.

15. Bosanac SS, Clark AK, Sivamani RK. Phytophotodermatitis related to carrot extract-containing sunscreen. Dermatol Online J. 2018;24:1-3.

16. Sforza M, Andjelkov K, Zaccheddu R. Severe burn on $81 \%$ of body surface after sun tanning. Ulus Travma Acil Cerrahi Derg. 2013;19:383-384.

17. Mioduszewski M, Beecker J. Phytophotodermatitis from making sangria: a phototoxic reaction to lime and lemon juice. CMAJ. 2015;187:756

18. Torrents R, Schmitt C, Domangé B, et al. Phytophotodermatitis with Peucedanum paniculatum: an endemic species to Corsica. Clin Toxicol (Phila). 2019;57:68-69.

19. Sarhane KA, Ibrahim A, Fagan SP, et al. Phytophotodermatitis. Eplasty. 2013;13:ic57.

20. DeLeo VA, Suarez SM, Maso MJ. Photoallergic contact dermatitis. results of photopatch testing in New York, 1985 to 1990. Arch Dermatol. 1992;128:1513-1518.

21. Kimyon RS, Warshaw EM. Airborne allergic contact dermatitis: management and responsible allergens on the American Contact Dermatitis Society Core Series. Dermatitis. 2019;30:106-115.

22. Miteva L, Broshtilova V, Schwartz RA. Unusual clinical manifestations of chronic discoid lupus erythematosus. Serbian J Dermatol Venereol. 2014;6:69-72

23. Handler NS, Handler MZ, Stephany MP, et al. Porphyria cutanea tarda: an intriguing genetic disease and marker. Int J Dermatol. 2017;56:E106-E117.

24. Papadopoulos AJ, Schwartz RA, Fekete Z, et al. Pseudoporphyria: an atypical variant resembling toxic epidermal necrolysis. J Cutan Med Surg. 2001;5:479-485

25. Jasterzbski TJ, Janniger EJ, Schwartz RA. Adolescent tanning practices: understanding the popularity of excessive ultraviolet light exposure. In: Oranje A, Al-Mutairi N, Shwayder T, eds. Practical Pediatric Dermatology. Controversies in Diagnosis and Treatment. Springer Verlag; 2016:177-185.

26. Lai YC, Janniger EJ, Schwartz RA. Solar protection policy in school children: proposals for progress. In: Oranje A, Al-Mutairi N, Shwayder T, eds. Practical Pediatric Dermatology. Controversies in Diagnosis and Treatment. Springer Verlag; 2016:165-176.

27. Lagey K, Duinslaeger L, Vanderkelen A. Burns induced by plants. Burns. 1995;21:542-543.

28. Redgrave N, Solomon J. Severe phytophotodermatitis from fig sap: a little known phenomenon. BMJ Case Rep. 2021;14:e238745. 